\title{
REQUISITOS Y EFECTOS DE LA INTERPOSICIÓN DEL RECURSO JERÁRQUICO
}

Fecha de recepción: 10 de noviembre de 2018

Fecha de aceptación y versión final: 9 de octubre de 2019

RESUMEN: Entre los medios de la justicia administrativa se encuentra el denominado recurso jerárquico. El conocimiento de los requisitos y efectos que la interposición de un recurso administrativo conlleva, resulta esencial para su correcta tramitación y resolución. Estos requisitos y efectos se encuentran previstos esencialmente en los cánones 1734-1738 del Código de Derecho Canónico.

PALABRAS CLAVE: derecho canónico; justicia administrativa; recurso jerárquico.

\section{Requeriments and Effects of Presentation of Hierarchical Resource}

ABSTRACT: Between the means available to administrative justice, it's found the so-called Hierarchical resource. The knowledge of the requirements and effects that the presentation supposes it is essencial for its correct processing. These requirements are foreseen in cc. 1734-1738 of the Code of Canon Law.

KEY WORDS: Canon Law; administrative justice; hierarchical resource.

\footnotetext{
" Real Centro Universitario Escorial-María Cristina: fjzamora@rcumariacristina.com; ORCID: https://orcid.org/0000-0003-0696-4778
} 


\section{EL RECURSO JERÁRQUICO COMO MEDIO DE JUSTICIA ADMINISTRATIVA}

En el Código de Derecho Canónico no se encuentra una definición de recurso jerárquico. Por esta razón, y acudiendo a las elaboraciones doctrinales, puede entenderse que es la impugnación de un acto administrativo ante el autor del acto o ante su superior jerárquico, circunstancia que implica su tramitación por la misma vía procedimental administrativa en la que se dictó ${ }^{1}$.

Así, el recurso jerárquico se configura como un medio de impugnación de un acto administrativo, es decir, un instrumento jurídico previsto en el ordenamiento canónico para rebatir actos de la potestad administrativa. En el orden expuesto, puede concebirse como un conjunto de actuaciones que conducen al fin pretendido, o si se prefiere, como un derecho de impugnación, que no es más que una manifestación concreta del derecho general a accionar o derecho a la tutela, atribuido a todos los fieles en virtud del canon $221 \S 1^{2}$, aunque condicionado a su reconocimiento por las disposiciones del Código de Derecho Canónico y al cumplimiento para su ejercicio de los requisitos legales que procedan.

En todo caso, el recurso jerárquico debe estimarse como un medio más de justicia administrativa ${ }^{3}$, si bien, carente de naturaleza judicial. Por justicia administrativa es posible entender el conjunto de medios que el derecho positivo otorga a los administrados para impugnar aquellas decisiones de la Administración que estimen contrarias a la legalidad

1 Vid. Eduardo Labandeira, en Manual de Derecho Canónico, Juan Ignacio Arrieta et al., obra a cargo del Instituto Martín de Azpilcueta (Pamplona: EUNSA, 1988), 750; y "El recurso jerárquico ante la Curia Romana", Ius Canonicum 30 (1990): 750.

2 Can. 221 §1 CIC: "Compete a los fieles reclamar legítimamente los derechos que tienen en la Iglesia, y defenderlos en el fuero eclesiástico competente conforme a la norma de derecho». Para el presente trabajo se ha utilizado la traducción del Códex Iuris Canonici a lengua española realizada en Código de Derecho Canónico. Edición bilingüe, ed. Profesores de la Univ. Pontificia de Salamanca y de la Univ. de Navarra (Madrid: BAC, 2015).

${ }_{3}$ Gian Paolo Montini así lo entiende, cuando afirma que: «Per giustizia ammnistrativa in questo contributo si intende abbracciare tutti gli strumenti previsti dall'ordinamento canonico per la soluzione di controversie sorte da un atto della potestà amministrativa. Si intendono perciò comprensi anche i ricorsi gerarchini e gli strumenti di conciliazioni». Gian Paolo Montini, "La giustizia ammnistrativa dal Concilio al Codice", Periodica 102 (2013): 641. 
o a sus legítimos intereses ${ }^{4}$. La Parte V del Libro VII del Código de Derecho Canónico está dedicada a la regulación del procedimiento en los recursos administrativos y en la remoción o el traslado de los párrocos, comprendiendo una sección I bajo la rúbrica "Del recurso contra los decretos administrativos" (cann. 1732-1739). En estas normas se prevé que quien se considera perjudicado por un decreto, puede recurrir por cualquier motivo al superior jerárquico de quien emitió el decreto ${ }^{5}$, señalándose la forma procedimental que deberá seguirse para tal fin. Se trata de una normativa escueta que, si bien implica un notorio avance respecto de la regulación precedente, no deja de ser excesivamente breve.

La importancia que el recurso jerárquico tiene a la hora de la defensa de los derechos de los administrados es fundamental ${ }^{6} \mathrm{y}$, sin embargo,

${ }^{4}$ Vid. Rafael Entrena Cuesta, Curso de Derecho Administrativo, v. I/I, 13. ${ }^{\mathrm{a}}$ ed. (Madrid: Editorial Tecnos, 1999), 273.

5 Cfr. can. 1737.

${ }^{6}$ Entre los trabajos dedicados al recurso jerárquico, cabe citar los siguientes: Eduardo Baura, "I ricorsi gerarchici", en Il diritto nel mistero della Chiesa: Prassi amministrativa e procedure speciali, Gruppo Italiano docenti di diritto canonico (Città del Vaticano: Pontificium Institutum Utrusque Iuris, 2014), 115-134; Jonh P. Beal, "Hierchical Recourse: Procedures at local level", CLSA Proceedings, 62 (2000): 93106; Estanislao Olivares D'Angelo, "Recurso contra los actos administrativos (Recursus administrativus)", en Diccionario de Derecho Canónico, dir. Carlos Corral y José María Urteaga Embid (Madrid: Tecnos, 1989), 532-533; Zenon Grocholewski, "Atti e ricorsi amministrativi", Apollinaris 57 (1984): 258-279; e "Il sistema dei recorsi e la giurisdizione dei tribunal admministrativi”, en I principi per la revisione del códice di diritto canonico. La recezione giuridica del Concilio Vaticano II, a cura di Javier Canosa (Milano: Pont. Univ. Santa Croce, 2000), 461-499; C. Gullo, "Il ricorso gerarchico: procedura e decisione”, en VV. AA., La giustizia ammnistrativa nella Chiesa (Città del Vaticano: Librería Editrice Vaticana 1991), 85-96; K. Martens, "Protection of Rights: Experiences with Hiercachical Recourse and Possibilities for the Future", Jur 69 (2009): 646-707; Jonh P. Beal, "Hierchical Recourse: Procedures at local level", CLSA Proceedings, 62 (2000): 93-106; Gian Paolo Montini, "Modalità procedurali e processuali per la difesa dei diritti dei fedeli. Il ricorso gerarchico. Il ricorso alla Segnatura Apostolica”, Quaderni di diritto ecclesiale 8 (1995): 287-320; Luis Bernando Mur Malagón, "Del recurso contra los decretos administrativos (Cann. 1732-1739)", Universitas Canonica 44 (2011): 233-256; Miguel Ángel Ortiz, "I ricorsi gerarchici", en Gruppo Italiano Docenti di Diritto Canonico, I giudizi nella Chiesa. Processi e procedure speciali. Processi e procedure speciali. XXV Incontro di Studio. Villa S. Giuseppe - Torino 29 giugno-3 luglio 1998 (Edizione Glossa: Milano, 1999); Pio Vito Pinto, "El recurso jerárquico", Revista Mexicana de Derecho Canónico 16 (2010): 37-62; Michel Thériault, "La procédure des Recours Administratifs: Survol et Évaluation", CLSA Proceedings 57 (1995): 387-427; P. Valadrini, "Les recours canonques offerts 
se trata de una institución jurídica escasamente conocida y utilizada. Eduardo Labandeira se ha hecho eco de esta realidad, afirmando que «la práctica de los recursos en la Iglesia nos es poco conocida, lo cual es un dato que juzgamos negativo para la existencia de justicia en su seno» ${ }^{7}$.

Pues bien, la eficacia del recurso jerárquico como medio e instrumento de la justicia administrativa al servicio de los administrados, depende del momento de su presentación ante la autoridad competente. Con este acto se activa el procedimiento que culminará, por lo general, con el decreto resolutorio que en su momento dicte el superior jerárquico. El estudio y la determinación de los requisitos requeridos para la presentación del recurso jerárquico, junto a los importantes efectos que provoca en su tramitación, constituyen el objeto del presente trabajo, procurando una visión que conjugue las explicaciones doctrinales con la realidad práctica.

\section{FORMA Y CONTENIDO}

En los cánones relativos al procedimiento a seguir en los recursos administrativos no se especifica la forma ni el contenido que los mismos deben adoptar ${ }^{8}$. Parece clara la exigencia de que los recursos se presenten por escrito. Así se deduce de la previsión del canon 1734 §1 para la solicitud previa de reforma o enmienda: «el interesado debe solicitar a su autor por escrito la revocación o enmienda del decreto». Resulta evidente que si este acto previo y preparatorio requiere escritura, con más razón se exigirá para el recurso jerárquico9. En lo demás, existe una cierta libertad de forma. Ahora bien, al margen de esta libertad,

\footnotetext{
aux animateurs pastoraux", AC 35 (1992): 55-60; y Francisco José Zamora García, "Resolución del recurso jerárquico canónico", Anuario de Derecho Canónico, de la Universidad Católica de Valencia 6 (2017): 15-48.

7 Eduardo Labandeira, "La defensa de los administrados en el Derecho Canónico", Ius Canonicum 61 (1991): 272.

${ }^{8}$ Cfr. cann. 1732-1739 CIC.

9 Con carácter excepcional, en aquellos casos en los que el perjudicado tenga un impedimento grave para presentar por escrito el recurso, cabe entender que puede admitirse una petición oral, acordándose que un notario levante acta, que deberá ser leída al recurrente y aprobada por este, y que sustituirá el escrito del recurso a todos los efectos jurídicos. Se trata de una aplicación analógica de lo previsto para los escritos de demanda en el can. 1503 CIC.
} 
pueden señalarse algunos elementos constitutivos que necesariamente deberán estar presentes en el escrito interpuesto por el perjudicado, y mediante el cual solicita la reforma o enmienda de un acto administrativo adverso ante el superior jerárquico encargado de resolver el recurso. Estos elementos pueden clasificarse como subjetivos, objetivos, jurídicos y petitorios. Y aún cabe añadir algunos más de carácter menor. A la conclusión expuesta se llega trasladando la doctrina elaborada con ocasión de las demandas judiciales, siendo razonable estimarla de aplicación a la materia administrativa, naturalmente con las preceptivas adaptaciones.

\subsection{Elementos subJetivos}

Los elementos subjetivos son los que permiten la identificación del sujeto recurrente, del sujeto recurrido y de la autoridad encargada de resolver el recurso jerárquico interpuesto. Es obvio que nunca podrán omitirse y su ausencia implicará la inadmisión irremediable del recurso. No puede extrañar que la doctrina resalte la importancia que estos elementos subjetivos tienen para la correcta tramitación y resolución del recurso jerárquico ${ }^{10}$. En consecuencia, el recurrente hará constar sus datos personales en el escrito, indicando nombre y apellidos y, en su caso, la razón social, así como su domicilio, ya se trate de una persona física o de una jurídica. En ninguna ocasión puede obviarse la reseña de un domicilio, dada la trascendencia que tiene para la práctica de notificaciones posteriores. En los supuestos que se actúe por representación de una persona física o jurídica deberá reseñarse el título legítimo de esta función. Asimismo, el recurrente deberá indicar los datos que permitan la identificación de la autoridad que ha dictado el acto administrativo cuestionado, requisito imprescindible para la determinación del superior jerárquico que decidirá el recurso. No se trata de señalar los datos personales de dicha autoridad, sino constatar aquellos que permitan su correcta identificación dentro de la estructura jerárquica de la Iglesia. El

${ }_{10}$ Así lo hace, por ejemplo, Eduardo Labandeira, cuando escribe: «En el escrito del recurso deben consignarse todos los datos que permitan identificar el asunto: el acto administrativo y su autor, los datos personales del recurrente, los motivos por los que recurre y la petición que hace al superior jerárquico». Labandeira, "Manual de Derecho Canónico”, 755. 
tercer elemento subjetivo requerido es, precisamente, la identificación del superior encargado legalmente de resolver el recurso jerárquico, puesto que, entre otras razones, el escrito del recurso deberá dirigirse al mismo. Aquí sucede otro tanto, porque solo interesan los datos relativos al superior jerárquico en cuanto que desempeña un determinado oficio, y no los correspondientes a su persona física.

\subsection{Elementos objetivos}

Los elementos objetivos consisten en la petición o peticiones concretas formuladas por el recurrente. Es decir, se trata del objeto inmediato que motiva la interposición del recurso jerárquico. La fórmula debe ser clara, instando la revocación o enmienda del acto administrativo que se estima perjudicial para el interesado. Debe contenerse una referencia suficiente del acto administrativo recurrido que posibilite su correcta identificación, así como reseñar sucintamente los motivos por los que el recurrente se siente perjudicado en algún derecho o interés personal, directo, actual y tutelado por la norma directa o indirectamente ${ }^{11}$. También conviene describir aquellas circunstancias que relacionadas con el asunto ayuden a concretar la cuestión jurídica planteada y pretendida.

\subsection{ELEMENTOS JURídicos}

En el escrito del recurso jerárquico es conveniente exponer, siquiera de forma sucinta, los fundamentos jurídicos de la pretensión instada. Se trata de las normas legales que son aplicables al supuesto de hecho específico planteado. Para la concurrencia del fumus boni iuris debe quedar establecida la relación entre la base jurídica que sustenta la petición, norma o resolución, y los hechos en que se ampara la pretensión del recurrente. No se requiere anticipar las pruebas de que el perjudicado pretenda valerse, aunque sí, en su caso, instar su práctica durante la sustanciación del recurso. En toda circunstancia debe acompañarse la documentación que pueda apoyar los argumentos esgrimidos, o cuando

${ }^{11}$ Vid. Manuel Jesús Arroba Conde, sub. can. 1735, en Código de Derecho Canónico. Edición bilingüe, fuentes y comentarios de todos los cánones, dir. Antonio Benlloch Poveda (Valencia: EDICEP, 1993), 745. 
menos indicarla, ya que en el breve plazo señalado para la presentación del recurso puede que no sea fácil obtenerla, y siempre cabe presentarla una vez admitido a trámite el recurso, en los plazos que señale el superior competente para resolver ${ }^{12}$. Igual tratamiento debe darse en el caso de que el recurrente no pueda acceder a la documentación que precise, señalando el archivo o protocolo donde se encuentre a los efectos oportunos. En cualquier caso, la fundamentación jurídica no tiene por qué ser profusa ni detallada, especialmente si el sujeto que recurre interviene sin la asistencia de un abogado. Es más, tampoco es imprescindible, siendo de aplicación plena el principio de que iura novit curia, lo que evita la necesidad de profusión en los fundamentos y argumentaciones jurídicas.

\subsection{Elementos PEtitorios}

Si bien el objeto inmediato del recurso jerárquico es la revocación o enmienda de un acto administrativo estimado adverso, su plasmación inmediata se lleva a cabo a través de la invocación al ministerio del superior que debe resolverlo. Se trata de un elemento verdaderamente decisivo $^{13}$, en cuanto que en este procedimiento el recurso se dirige a la competente autoridad eclesial superior, y no al autor del acto recurrido, como sucede en los recursos de reposición de los ordenamientos administrativos seculares y en la previa petición de revocación o enmienda al autor del acto, y que está prevista en el canon $1734^{14}$. No hay ningún

12 Según Luis Bernardo Mur Malagón, se trata de «copia de documentos (escrituras de propiedad, contratos, estatutos, decretos de nombramiento, actos, certificaciones, entre otras) que respalden la situación jurídica en virtud de la cual el interesado se considera legitimado para recurrir, o al menos el elenco de la documentación que podrá aportarse, de ser requerida». Mur Malagón, "Del recurso contra los decretos administrativos (Cann. 1732-1739)", 252.

13 Eduardo Labandeira resalta esta idea, afirmando que «El recurso jerárquico es una actividad administrativa de control, contenciosa a instancia de interesado. De control, porque se revisa un acto anterior; contenciosa a instancia de interesado, en lo que tiene gran similitud con la actividad judicial, cuyo objeto es "la reclamación o reivindicación de derechos de personas físicas o jurídicas, o la declaración de hechos jurídicos" (c. 1400 §1,1)». Labandeira, "El recurso ante la Curia Romana”, 454.

14 Los denominados recursos de reposición, previstos en los ordenamientos seculares, se interponen ante el autor del acto cuestionado, que además es el competente 
obstáculo para que, en caso de estimarse conveniente y justo por el interesado, pueda solicitarse también la reclamación de resarcimiento por los daños eventualmente causados por el acto administrativo objeto del recurso interpuesto ${ }^{15}$.

\subsection{Otros ElEmentos}

El escrito de formalización del recurso administrativo debe ser firmado y fechado por el recurrente, y en el supuesto de que concurra causa para ello, por su representante legal o patrono. También deberá acompañarse de los documentos auténticos en los que se confiera mandatos a los abogados y procuradores, en el caso de que el recurrente quiera servirse de ellos ${ }^{16}$. Por otro lado, si no se suspendió automáticamente la ejecución del acto impugnado ${ }^{17}$, ni se acordó tampoco la suspensión provisional en la fase preparatoria del recurso, puede pedirse de nuevo a la hora de su interposición, ya que el superior que lo resuelve tiene facultad para acordarla de oficio o a instancia del sujeto recurrente ${ }^{18}$. Más adelante se volverá sobre el asunto, que no carece de importancia. Igualmente, y en aquellos casos en que sea preceptivo de conformidad a las previsiones del canon 1734, deberá adjuntarse al recurso el escrito que justifique haber realizado la petición previa de revocación o enmienda al autor del acto que ahora se recurre, así como el decreto desestimatorio de la misma ${ }^{19}$. Asimismo, en el escrito podrá reseñarse las personas que deberán oírse preceptivamente, si sus derechos pueden resultar lesionados ${ }^{20}$.

para su resolución. Por el contrario, el recurso jerárquico entra dentro de la categoría de los recursos de alzada.

15 Cfr. can. 128 CIC.

16 Cfr. can. 1738 CIC.

17 Cfr. can. 1736 §1 CIC.

18 Cfr. can. 1738 §3 CIC.

19 En el caso de que el autor del acto, una vez recibida la petición de revocación o enmienda, haya dejado transcurrir el plazo previsto en el can. 1734 CIC sin intimar un nuevo decreto, ya sea estimatorio o desestimatorio, el recurrente deberá reseñar esta circunstancia en el recurso.

20 Cfr. can. 50 CIC. 


\section{ASISTENCIA DE ABOGADO Y PROCURADOR}

\subsection{JuSTIFICACIÓN}

Se dispone en el canon 1738 que «el recurrente tiene siempre derecho a servirse de un abogado o procurador». Pues bien, de conformidad con las categorías utilizadas usualmente en el derecho procesal, se entiende por "postulación» la intervención en un proceso judicial o administrativo de personas expertas, profesionales o no, que vienen a colaborar con las partes en determinados actos de aquella naturaleza ${ }^{21}$. Según las previsiones del Código de Derecho Canónico, la postulación también puede estar presente en la tramitación de los recursos jerárquicos, ajustándose a las reglas y categorías que más adelante se expondrán ${ }^{22}$. Pero con carácter previo, cabe reflexionar sobre el significado y justificación que esta postulación tiene en la tramitación del recurso.

En primer lugar, la posible intervención de abogado y procurador anuncia la complejidad propia de los litigios administrativos, que no tiene que por qué ser menor de la que concurre en los procesos de naturaleza judicial. En segundo lugar, da idea aproximada de la importancia de las materias que pueden ventilarse en un recurso jerárquico, ya que, por tratarse de aplicación de normas de derecho administrativo y, por consiguiente, relacionarse con el bien común de la comunidad, ostentan una trascendencia que va más allá del singular interés particular de las partes. En tercer lugar, describe con claridad los términos en los que se plantea el litigio administrativo, y que no son otros que un verdadero y auténtico contradictorio ${ }^{23}$. Finalmente, y en cuarto lugar,

${ }^{21}$ Vid. Leonardo Prieto Castro, Tribunales españoles. Organización y funcionamiento (Madrid: Editorial Tecnos, 1974), 82ss.

22 Pio Vito Pinto afirma: «El canon introduce una norma de gran importancia, que era impensable hace 40 años. El recurrente puede ahora valerse de la asistencia de un abogado o de un procurador». Pinto, "El recurso jerárquico", 52.

${ }^{23}$ Manuel Jesús Arroba Conde escribe: «Aun no tratándose de un proceso judicial, el recurso jerárquico implica la puesta en marcha de muchos mecanismos tendentes a comprobar la justicia e ilegalidad del acto administrativo impugnado, así como la ponderación de los argumentos defensivos del recurrente. Por ello, aun siendo administrativo, el recurso jerárquico contiene un verdadero contradictorio, en virtud del cual se concede al recurrente (y al superior, si lo desea) aconsejarse con la ayuda de un abogado, e incluso nombrarlo de oficio, si el superior lo cree necesario». Arroba, sub. can. 1738, 745. 
apercibe sobre la preocupación del legislador a la hora de salvaguardar eficientemente los derechos de los miembros de la Iglesia, partiendo del entendimiento del recurso jerárquico como un eficaz instrumento de tutela de los derechos de los fieles. Por ello, cabe revestir a los sucesivos actos de la tramitación del recurso de importantes cautelas jurídicas, como las que proporcionan la intervención de abogados y procuradores ${ }^{24}$.

La postulación es, pues, una garantía de calidad técnica, pero también del asesoramiento especializado a los sujetos intervinientes en ejercicio de su legítimo e irrenunciable derecho de defensa, circunstancia que adquiere especial significación cuando el administrado se enfrenta jurídicamente a una Administración situada por su propia naturaleza en un plano jerárquico muy superior. Seguramente, porque la intervención de los abogados y procuradores en este procedimiento no es preceptiva, no es frecuente su utilización en los recursos jerárquicos, salvo aquellos que se interponen ante las congregaciones romanas. Quizás por ello, la doctrina ha prestado escasa atención a la función que estos profesionales pueden desempeñar en la presentación y posterior tramitación de los recursos jerárquicos, circunstancia que recomienda dedicar los siguientes párrafos a su estudio.

\subsection{CONFIGURACIÓN DEL ABOGADO Y DEL PROCURADOR}

Es frecuente que la postulación comprenda dos figuras diferentes. Por un lado, se encuentran los abogados, también denominados habitualmente como «letrados», que prestan asistencia técnica con sus conocimientos jurídicos y ofrecen garantías a la parte sobre el adecuado ejercicio de su derecho de defensa ${ }^{25}$. Por otro lado, se encuentran los procuradores o representantes procesales de la parte, que mediante un

${ }^{24}$ Diferente era la situación anterior al vigente CIC. Zenon Grocholewski, la describe así: «Ese sistema en realidad no ofrecía la posibilidad de una defensa adecuada: el recurrente, que normalmente no conoce la ley como un órgano administrativo, no tenía derecho a servirse de un abogado que pudiera ser adecuado interlocutor de la autoridad administrativa». Zenon Grocholewski, "Treinta años de justicia administrativa canónica. Balance y perspectivas”, Fidelium Iura 8 (1998): 271.

${ }_{25}$ Vid. Luigi De Luca, "L'avvocato tra il privato e l'autorità nell'ordinamento canonico", en Scritti vari di diritto ecclesiastico e canonico, v. 1, (Padova: Cedam, 1997). 
mandato legítimo colaboran en la tramitación procesal, facilitando la realización de los complejos trámites procesales ${ }^{26}$.

La función del abogado es de asistencia técnica, de consejo, estudio y elaboración de los diversos escritos. Es un trabajo de asesoramiento jurídico, requiriendo para su labor un mandato de la parte ${ }^{27}$. El procurador tiene principalmente una función representativa. Actúa en los procedimientos judiciales y administrativos por la parte y para la parte, en cuyo nombre y para quien presenta escritos y recibe notificaciones, salvo aquellas actividades en las que se exige una actuación directa. Para el cumplimiento de su oficio requiere un poder de representación de la parte en el procedimiento. Ambos oficios, aun siendo diferentes, pueden ser ejercidos y acumulados en la misma persona, empleándose casi siempre el término patrono en el ámbito canónico para comprender ambas funciones cuando vienen cubiertas por la misma persona ${ }^{28}$. Por lo demás, toda la materia relativa a los abogados y procuradores, se encuentra prevista y regulada con carácter general en los cánones 1481 a 1490, siendo de aplicación a su intervención en el procedimiento del recurso jerárquico con las debidas adecuaciones.

\subsection{INTERVENCIÓN NO PRECEPTIVA}

Como antes quedó reseñado, en el canon 1738 se admite expresamente la postulación del recurrente durante la tramitación del recurso jerárquico. Efectivamente, para la defensa de sus intereses, el fiel que recurre un acto de una autoridad eclesial tiene derecho a valerse en el procedimiento de los servicios de un abogado o procurador. Sobre este extremo el texto del canon es claro: «El recurrente tiene siempre derecho a servirse de un abogado o procurador». Son varios los comentarios que sugiere el citado precepto. En primer lugar, debe destacarse que el derecho conferido al recurrente alcanza a servirse de las dos figuras de la postulación: abogado y procurador. Sin embargo, de conformidad a

${ }^{26}$ Sobre todo, a la hora de las notificaciones. La utilización de un procurador facilita estos actos notablemente.

27 Vid. Carmelo De Diego-Lora, sub. can. 1482, en Código de Derecho Canónico. Edición anotada, a cargo de Pedro Lombardía y Juan Ignacio Arrieta (Pamplona: EUNSA, 2004), 892.

28 Arroba, sub. can. 1481, 656. 
la redacción del texto del canon y a los principios rectores del ordenamiento procesal canónico ${ }^{29}$, el recurrente puede servirse de ambas figuras conjuntamente, o bien, solo de abogado o de procurador. Incluso se admite que el abogado desempeñe a la misma vez las funciones propias del procurador.

En segundo lugar, conviene resaltar que el derecho a la asistencia técnica y representación en la tramitación del procedimiento del recurso jerárquico se configura en el código precisamente como un derecho, y no como una obligación. Corresponde al recurrente, en principio, adoptar la decisión de nombrar un abogado y, en su caso, un procurador. De esta forma, en el canon 1738 se recoge para los recursos jerárquicos la regla general vigente en el sistema procesal canónico, según la cual, salvo prescripción expresa en contra, quien tiene la condición de parte puede llevar a cabo personalmente toda la actividad que le corresponde en el proceso $^{30}$. Por otro lado, y sin perjuicio de que en el citado canon 1738 se guarde silencio, es evidente que respecto a la designación, cualidades, régimen y cesación de los abogados y procuradores serán de aplicación, ciertamente, las normas y disposiciones previstas en ordenamiento procesal canónico, y específicamente en los cánones referidos al proceso judicial ordinario ${ }^{31}$.

Como se sabe, en la resolución de un recurso contra un acto administrativo siempre está en juego de algún modo el bien público ${ }^{32}$, puesto que ese fin ha de presidir toda actuación legítima de la autoridad eclesiástica y, sin embargo, en el código no se impone la intervención de abogado y procurador. Esta opción difiere parcialmente de la prevista en el canon 1481, precepto correspondiente a las normas procesales canónicas. Efectivamente, en el ámbito de los juicios, la parte puede designar libremente su abogado y procurador, pero se señalan expresamente las siguiente excepciones: en el juicio penal el acusado debe tener siempre un abogado; en el juicio contencioso, si se trata de menores o de un juicio en el cual entra el bien público, salvo en las causas matrimoniales,

29 Cfr. cann. 1481-1490 CIC.

30 Cfr. can. 1481 § 1 CIC.

31 Cfr. cann. 1481-1490 CIC. Para profundizar en el conocimiento sobre la normativa procesal canónica relativa a los abogados y procuradores, y que es de aplicación en esta materia, vid. Juan José García Faílde, Nuevo Derecho Procesal Canónico (Salamanca: Ediciones UPSA, 1995), 49ss.

32 Zamora García, “Resolución del recurso jerárquico canónico”, 15-48. 
el juez ha de designar de oficio un defensor a la parte que no lo tiene ${ }^{33}$. Por consiguiente, en los procesos judiciales que entra en juego el bien público la parte deberá estar asistida de abogado, mientras que en los recursos administrativos o jerárquicos no necesariamente. El diferente tratamiento se palia con la posibilidad de su nombramiento de oficio en determinados supuestos, tal y como se verá seguidamente.

\subsection{Nombramiento DE OFICIO}

La intervención de abogado y procurador asistiendo a las partes que intervienen en la tramitación de un recurso jerárquico se muestra en numerosos casos muy conveniente, ya que las garantías del ejercicio de defensa y las complejidades jurídicas en cuestión pueden recomendarlo ${ }^{34}$. Así se hará más palpable la función tuitiva y garantizadora de los derechos que se pretende alcanzar a través de la tramitación del recurso jerárquico. Esto no quiere decir que en la mayoría de los recursos jerárquicos convenga el patronato, puesto que su sencillez o escasa trascendencia del asunto tratado lo hacen innecesario. Pero habrá otros casos en los que la complejidad técnica, la importancia y consecuencias de su resolución, lo requieran ${ }^{35}$. El legislador canónico, plenamente consciente de su conveniencia en estos supuestos, prevé en el mismo canon 1738 su posible constitución de oficio, designándose abogado o procurador de oficio ${ }^{36}$,

${ }^{33}$ En el c. 1481 CIC se dispone: «§1 La parte puede designar libremente su abogado y procurador, pero, salvo en los casos indicados en los $\$ \S 2$ y 3 , puede también demandar y contestar personalmente, a no ser que el juez considere necesaria la ayuda del procurador o del abogado. §2. En el juicio penal el acusado debe tener siempre un abogado, elegido por él mismo o nombrado por el juez. §3 En el juicio contencioso, si se trata de menores o de un juicio en el cual entra en juego el bien público, con excepción de las causas matrimoniales, el juez ha de designar de oficio un defensor a la parte que no lo tiene».

34 Sobre este aspecto, Luis Bernardo Mur Malagón escribe: «Es necesario subrayar que este recurso requerirá por parte del recurrente una específica preparación. Cuando no la hay se hace imprescindible la asistencia técnica que puede ofrecer un abogado». Mur Malagón, "Del recurso contra los decretos administrativos (Cann. 1732-1739)", 251.

35 Piénsese, por ejemplo, en el ámbito de los decretos penales.

36 Vid. J. Ochoa, "La figura canónica del procurador y abogado público", en $D i$ lexit Iustitiam. Studi in honorem Aurelii, Card. Sabattani, dir. Zenon Grocholewski y Vicente Cárcel Ortí (Città del Vaticano: Librería Editrice Vaticana, 1984), 249-284. 
como se dijo antes "patrono», en la terminología del código ${ }^{37}$, si el recurrente carece de ellos y el superior lo juzga necesario. No obstante, en el mismo canon se deja siempre a salvo la circunstancia de que el superior puede ordenar al recurrente que se presente personalmente para ser interrogado: «incluso debe designarse patrono de oficio, si el recurrente carece de él y el Superior lo considera necesario, pero en cualquier momento el Superior podrá ordenar que comparezca el mismo recurrente para ser interrogado», dice el texto del canon.

La posibilidad de que el superior nombre abogado o procurador de oficio si lo estima conveniente no debe entenderse en contradicción con el carácter no preceptivo de la asistencia técnica y procesal de las partes. Efectivamente, además del derecho del recurrente, el canon 1738 regula un deber y una facultad del superior jerárquico que ha de resolver el recurso, ya que tiene el deber de nombrar de oficio un patrono al recurrente si lo considera necesario y este no lo ha hecho. Se trata de evitar en todo caso la posible indefensión o desventaja que la ausencia de patrono pudiese producir en el recurrente cuando no se muestre capacitado para defender personalmente de manera adecuada sus intereses. Una vez más se pone de manifiesto la función tutelar que la institución del recurso jerárquico viene a desempeñar en el seno del ordenamiento canónico, ya que la protección de los derechos de la parte más indefensa es lo que motiva al legislador canónico a prever un posible nombramiento de abogado y procurador de oficio en estos casos.

La redacción del canon 1738 no deja claro el momento en que el nombramiento del patrono de oficio tendrá lugar. Es evidente que caben dos posibilidades. La primera es antes de presentar el recurso jerárquico, es decir, en esta opción la intervención del patrono tendrá como objeto participar en la redacción y confección del recurso, sin perjuicio de su asistencia a lo largo de la posterior tramitación ante el superior competente para resolver. Para que se produzca eficazmente esta solución, el fiel que pretende recurrir un acto administrativo deberá, con carácter previo,

37 Aunque no existe una completa unanimidad en la doctrina, el término «patrono» sirve para designar al abogado y al procurador. La expresión, pues, no alude a otra categoría sui generis de letrados, sino que designa a la vez a todo abogado y procurador. En consecuencia, deben aplicarse al patrono las normas dadas para cada uno de ellos, pero teniendo en cuenta cuál de las dos profesiones ejerce, o si ejerce las dos. Vid, Malaquías Zayas, "Abogados y Procuradores en los Tribunales Eclesiásticos”, Revista Jurídica de Cataluña 83 (1984): 202. 
instar al superior el nombramiento del patrono. La segunda posibilidad es que el recurrente confeccione, por sus propios medios, el recurso jerárquico, y una vez que haya sido presentado, el superior encargado de su resolución acuerde de oficio la conveniencia de nombrar patrono de cara a su posterior tramitación. Ambas posibilidades son admisibles y su concreción se hará según las circunstancias del supuesto planteado.

\subsection{FunCión EN EL CONTRADICTORIO}

Tal y como se ha dicho antes, la posible intervención de abogado y procurador en la tramitación de un recurso jerárquico es reveladora de las preocupaciones del legislador por configurar un procedimiento en los recursos administrativos investido de suficientes garantías, una vez advertido su carácter litigioso. Aun cuando la naturaleza de este recurso no sea judicial sino administrativa, no deja de ser cierto que su tramitación supone realizar una serie de actos dirigidos a probar la justicia, legalidad u oportunidad de un acto administrativo dictado por una autoridad eclesiástica y que ha sido legítimamente impugnado ${ }^{38}$. Para su sustanciación será necesario ponderar argumentos defensivos del recurrente fundados en hechos y normas jurídicas. Por esta razón, el recurso jerárquico, sin dejar de ser administrativo, implica un verdadero contradictorio, y durante su tramitación es loable que se conceda al recurrente, si lo estima adecuado, la asistencia de un abogado y procurador ${ }^{39}$.

Jorge Miras pondera y justifica esta opción en los siguientes términos: «Esta garantía del derecho a la representación letrada para el recurrente indica, ciertamente, que la sustanciación del recurso jerárquico posee un carácter propiamente contradictorio: las partes tienen la posibilidad de presentar alegaciones y pruebas a favor de sus intereses, y han de moverse en un contexto formal que requiere una específica preparación, por lo que en muchas ocasiones la intervención técnica del letrado será imprescindible ${ }^{40}$. Efectivamente, el derecho a intervenir

38 Arroba, sub. can. 1738, 745.

39 Se trata de una consecuencia del principio omme ius actione munitur, es decir, la ley concede el derecho individual o la capacidad del sujeto para defender un derecho. Vid. Pinto, "El recurso jerárquico", 52.

40 Jorge Miras en Jorge Miras, Javier Canosa y Eduardo Baura, Compendio de derecho administrativo canónico (Pamplona: EUNSA, 2001), 272-273. 
en todo el procedimiento del recurso jerárquico asistido de abogado y procurador indica claramente el carácter contradictorio propio de este procedimiento, sin perjuicio de su brevedad y de carecer de la solemnidad y formalismo propios de los litigios de naturaleza judicial ${ }^{41}$. Pero, al mismo tiempo, se muestra con claridad como una necesidad derivada de las posibles complejidades derivadas del mismo contradictorio. Ambas dimensiones de la postulación, tanto la referida al asesoramiento técnico-legal, como la propia de la representación, quedan recogidas en la previsión del canon 1738.

Respecto al alcance de su intervención, debe ir más allá de la mera redacción del escrito del recurso. Según Zenon Grocholewski, también comprenderá lo siguiente: «Por principio, debe reconocerse al abogado el derecho de examinar las actas, con mayor razón tratándose de abogados que, en cuanto aprobados, gozan de la confianza de la autoridad eclesiástica y, además, pueden ser obligados bajo juramento a guardar secreto (cfr. c. 1455 §3), así como, por motivos graves, ser eliminados del elenco» ${ }^{42}$.

Ahora bien, y aunque parezca innecesario, debe destacarse que la intervención de abogado y procurador junto a los sujetos del procedimiento constituye una función de auxilio y colaboración con los mismos, no llegando a adquirir esta condición en ningún caso. Es más, su labor no debe llegar a suplantar ni anular la personalidad del recurrente que utiliza sus servicios profesionales, correspondiendo exclusivamente a él las decisiones últimas que el ordenamiento le reconoce sobre la tramitación del recurso. Además, y en esta dirección, en el mismo canon 1738 se prevé que «en cualquier momento el Superior podrá ordenar que comparezca el mismo recurrente para ser interrogado». Se trata de un acto personalísimo en el que usualmente no cabe delegación al representante. De acordarse el interrogatorio por el superior competente para resolver, la parte deberá acudir y deponer personalmente.

${ }^{41}$ Vid. Eduardo Labandeira, sub. can. 1738, en Código de Derecho Canónico. Edición anotada, a cargo de Pedro Lombardía y Juan Ignacio Arrieta (Pamplona: EUNSA, 2004), 1041.

42 Grocholewski, "Treinta años de justicia administrativa canónica. Balance y perspectivas", 281. En el mismo sentido se manifiesta Pio Vito Pinto, cuando estima que los abogados deben tener la facultad de conocer todos los actos del procedimiento. Pinto, "El recurso jerárquico", 52. 


\subsection{UTILIZACIÓN POR LA AUTORIDAD RECURRIDA}

En la resolución de un recurso contra un acto administrativo siempre está en juego, o puede estarlo de algún modo, el bien público, puesto que ese fin ha de presidir toda actuación legítima de la autoridad eclesiástica. Sin embargo, en el Código de Derecho Canónico no se impone la intervención de abogado y procurador asistiendo preceptivamente al recurrido o resistente, es decir, al autor del acto impugnado. Si bien, nada se dice en el canon 1738 sobre la eventual utilización de abogado y procurador por la autoridad de la que ha emanado el acto administrativo recurrido, tampoco se encuentra ningún obstáculo para admitir su posibilidad, independientemente de que en la práctica la utilización de un abogado y procurador por la autoridad recurrida no sea habitual.

Eduardo Labandeira estima que en principio los intereses que representa el autor del acto impugnado pueden ser debida y eficazmente tutelados por el superior jerárquico que resuelve el recurso, lo cual no impide que, en ocasiones, aquél sea asistido por un abogado y representado por un procurador ${ }^{43}$. Ahora bien, la admisión de esta identificación de intereses singulares y concretos entre una y otra autoridad eclesial haría inútil la tutela pretendida con el recurso jerárquico, siendo suficiente con la que pudiese derivarse de un recurso de reposición ${ }^{44}$. Incluso, podría llegar a condicionar decisivamente el contenido del acto resolutorio, tendiendo siempre a confirmar el decreto objeto de recurso. Es necesario, pues, encontrar otra fundamentación.

Jorge Miras, argumenta de la siguiente forma las razones que pueden haber asistido al legislador sobre este extremo: «Se justifica, probablemente, por dos razones: en primer lugar, porque se supone al autor del acto administrativo la capacidad de tutelar la parcela del bien público afectada - que es "su interés" en estos casos- por sí mismo. En segundo lugar, porque el superior que resuelve el recurso tiene también, por su oficio, la función de velar por esos mismos bienes. Por tanto, la no intervención de abogado o procurador por parte de la autoridad cuyo acto se impugna no tiene por qué poner necesariamente en peligro el bien público en juego. No obstante, nada impide tampoco que el autor

\footnotetext{
43 Vid. Labandeira, sub. can. 1738, 1042.

${ }_{44}$ Otra cosa es que todas las autoridades eclesiásticas deban velar por bien público y los intereses generales.
} 
del acto impugnado sea representado por un abogado o procurador, si lo estima oportuno» ${ }^{45}$.

Independientemente de la porción del bien público que se vea afectada en un recurso jerárquico contra un acto administrativo, y de la correlativa obligación de su tutela que corresponda a todas las autoridades en la Iglesia, los intereses referidos al supuesto concreto ventilado en la tramitación del recurso no implican la inmediata identificación entre el superior recurrido y el superior competente para resolver. Lo contrario, como se ha dicho, convertiría en inútil la alzada y el efecto devolutivo que el recurso jerárquico conlleva. Por ello, la autoridad recurrida se sitúa ante la autoridad que debe resolver en un cierto plano de igualdad con el sujeto recurrente, de modo tal que en ningún caso corresponde al superior jerárquico tutelar los derechos del recurrido de una manera automática e inevitable. La consecuencia de esta conclusión es inmediata, puesto que para el recurrido concurrirán las mismas razones que en su lugar se expusieron a favor de admitir el derecho que corresponde al recurrente para ser asistido de abogado y procurador.

Queda claro que el autor del acto administrativo recurrido, si lo estima conveniente, podrá servirse de abogado y procurador ${ }^{46}$. Es un derecho que no debe negarse, pero que en la práctica no será ejercido en la mayoría de los casos. El conocimiento del ordenamiento canónico que, en principio, se presume de toda autoridad, así como la propia estructura eclesial, con domicilios fijos y, en numerosos casos, los debidos asesoramientos por parte de la Vicaría judicial, evitan el ejercicio por la autoridad recurrida del derecho a la asistencia técnica y a la representación en los recursos jerárquicos. De hecho, no deja de ser significativo que en el canon 1738 no se prevea su posible nombramiento de oficio para el recurrido, a diferencia de lo que se prevé para el sujeto recurrente. Por consiguiente, la posibilidad de que ambos sujetos intervinientes en el procedimiento del recurso jerárquico puedan servirse de asistencia técnica a través de la intervención de abogados y procuradores, adquiere una importancia nada desdeñable, no solo desde el punto de vista práctico, sino también desde la óptica doctrinal. Y es que es una característica común de los procedimientos canónicos judiciales y del procedimiento

\footnotetext{
45 Miras, “Compendio de derecho administrativo canónico", 274.

46 Manuel Jesús Arroba Conde así lo estima, cuando afirma que el recurso jerárquico contiene un contradictorio, «en virtud del cual se concede al recurrente (ya al superior, si lo desea) aconsejarse con la ayuda de un abogado». Arroba, sub. can. 1738, 745. 
administrativo para resolver un recurso jerárquico, es la de garantizar el derecho de defensa, el ius defensionis, desde el principio mediante la eventual intervención de abogado y procurador ${ }^{47}$.

\subsection{CAutela NeCESARia}

Finalmente, es necesario hacer referencia a la última previsión contenida en el canon 1738. En este canon se prevé una cautela interesante y oportuna, ya que la intervención de abogado y procurador en la tramitación del recurso jerárquico en ningún caso debe producir dilaciones inútiles causadas por su negligente o dolosa actitud ${ }^{48}$. Se trata, pues, de una llamada a la cordura, a la racional intervención profesional y al destierro de prácticas forenses tendentes a restar celeridad a la resolución del recurso. Una opción distinta impediría alcanzar la ansiada dimensión tutelar de los derechos que corresponde al recurso jerárquico, es más, supondría utilizarlo como instrumento de su negación. El saber, juicio y deontología profesionales que corresponde a los abogados y procuradores en el ejercicio de sus oficios debe impedir toda dilación o retraso culpable o doloso ${ }^{49}$.

${ }^{47}$ La vinculación que existe entre la justicia administrativa y los derechos de los fieles es evidente, y en la misma, la eventual intervención de abogado y procurador aparece como fundamental. Al respecto, Zenon Grocholewski considera: «También en la literatura canónica los autores conectaban comúnmente, y conectan, la correcta orientación de la justicia administrativa en la Iglesia con la relevancia de los derechos de los fieles, que podría correr el riesgo de quedar en letra muerta si no existiese una adecuada posibilidad de defenderlos». Grocholewski, "Treinta años de justicia administrativa canónica. Balance y perspectivas", 273.

${ }^{48} \mathrm{Al}$ respecto, Eduardo Labandeira escribe: "Debe armonizarse el principio de protección debida con los de brevedad y economía procedimental, sin perjuicio de la facultad que tiene el recurrente para hacerse asistir de abogado y procurador". Eduardo Labandeira, Tratado de Derecho Administrativo Canónico, 2. ${ }^{\text {a ed. (Pamplona: }}$ EUNSA, 1993), 425.

49 De hecho, cabe estimar de aplicación por analogía el can. 1478 CIC, y, en su virtud, aceptarse que el superior competente para la resolución del recurso jerárquico pueda rechazar mediante decreto al abogado o procurador, tanto de oficio como a instancia de parte, pero siempre por causa grave, como sería un incumplimiento reiterado y contundente de la previsión contenida en el can. 1738 CIC sobre las dilaciones indebidas. 
Ahora bien, algún autor ha señalado que el inciso «pero evitando dilaciones inútiles» no puede interpretarse como una fórmula restrictiva del derecho a la asistencia letrada que se da siempre en el recurso, sino simplemente una exhortación en la línea del principio de celeridad que preside el procedimiento administrativo. Respecto a este asunto, Jorge Miras aporta las siguientes reflexiones: «Por tanto, si el recurrente estima que ha de valerse de abogado y procurador, el superior que resuelve el recurso no puede oponerse a ello. A lo sumo, podrá ejercer una actividad impulsora u ordenadora del procedimiento, velando para que no se produzcan demoras que no sean estrictamente necesarias, pero siempre sin causar indefensión ${ }^{50}$. Es un matiz muy interesante y que necesariamente debe compartirse.

\section{INTERPOSICIÓN}

Una vez realizados los trámites reseñados en el canon 1734, es decir, la solicitud previa de revocación o enmienda del decreto, que indudablemente tiene un carácter preparatorio de la tramitación, el perjudicado podrá interponer el recurso administrativo ante el superior jerárquico de la autoridad que dictó el acto ${ }^{51}$. Ahora bien, deberá hacerlo dentro del plazo legalmente previsto en el Código de Derecho Canónico ${ }^{52}$. Por esta razón, todo lo relativo a la presentación y el cumplimiento de dicho plazo resulta esencial en el procedimiento de tramitación del recurso jerárquico. La norma principal a este respecto es el canon $1737 \S 1$, cuyo texto es: «Quien se considera perjudicado por un decreto, puede recurrir por cualquier motivo justo al Superior jerárquico de quien emitió el decreto; el recurso puede interponerse ante el mismo autor del decreto, quien inmediatamente debe transmitirlo al superior jerárquico».

Es evidente que, si el autor del acto accede a la petición previa de revocación o enmienda, bien a instancia del interesado, bien a propuesta

\footnotetext{
50 Miras, “Compendio de derecho administrativo canónico”, 272.

51 En el can. 1734 §3 CIC se reseñan los casos en los que no es necesario realizar esta petición previa de revocación o enmienda.

52 Tal y como afirma Lamberto de Echevarría, con la interposición se inicia el recurso propiamente dicho. Lamberto De Echevarría, sub. can. 1737, en Código de Derecho Canónico. Edición comentada, dir. Lamberto De Echevarría (Madrid: BAC, 1984), 839.
} 
del departamento o consejo de mediación previsto en el canon 1733 §2, el conflicto desaparece y el procedimiento deja de tramitarse. Pero si no es esta la situación, la decisión de presentar el recurso en este momento puede responder a varias razones. La primera encuentra su justificación cuando el autor del acto, en el plazo de treinta días desde que recibió la petición de revocación o enmienda del mismo, la rechazó. También si guardó silencio durante el mismo plazo, no decidiendo en sentido alguno, pues se aplicaría la doctrina del silencio administrativo negativo ${ }^{53}$. La segunda razón tiene su justificación cuando el superior que dictó el acto accedió a su enmienda, pero el fiel se siente todavía perjudicado por su decisión, estimando la reforma concedida como insuficiente o inconveniente. Sea por un motivo u otro, la presentación del recurso jerárquico motiva seguidamente el estudio de tres aspectos relacionados con la misma, y que, como ya se ha dicho antes, adquieren una vital importancia en la tramitación del procedimiento: los plazos para recurrir, la determinación la autoridad ante la que debe presentarse y la apreciación y subsanación de defectos formales, en su caso ${ }^{54}$.

\subsection{Plazos Para Recurrir}

La primera de las cuestiones planteadas se refiere a los plazos previstos para recurrir un acto administrativo. Pues bien, el recurso jerárquico debe presentarse ante la autoridad competente para su recepción en el plazo previsto en el Código de Derecho Canónico, señalándose varios días de su inicio en función de las diferentes circunstancias que pueden concurrir. Efectivamente, en el canon 1737 se fija la regla general, y según se señala en su texto, consiste en que el recurso jerárquico ha de interponerse en el plazo perentorio de quince días útiles ${ }^{55}$. Ahora bien, ¿desde cuándo comienza a transcurrir el plazo de quince días señalado

53 Cfr. can. 57 CIC.

54 El recurso puede entregarse en mano en la Cancillería correspondiente, o enviarse por correo certificado con acuse de recibo, cuya fecha hace fe de haberlo interpuesto en tiempo oportuno. Vid. Labandeira, "Tratado de Derecho Administrativo Canónico", 437.

55 En el can. 1737 §2 CIC se dispone: «El recurso ha de interponerse en el plazo perentorio de quince días útiles, que, en los casos de que se trata en el c. $1734 \S 3$ corren desde el día en que el decreto ha sido intimado, y en los demás casos, conforme al canon $1735 »$. 
con carácter general en el referido canon? En aquellos supuestos en los que no es necesario interponer la solicitud previa de reforma o enmienda prevista en el canon 1734, desde el día en que se notificó el acto administrativo objeto del recurso. En los casos en que sí es preceptiva la interposición de reforma o enmienda prevista en el canon 1734 caben dos posibilidades ${ }^{56}$ :

a) Si el autor del decreto, en el plazo de treinta días desde que recibió la petición intima un nuevo decreto por el que corrige el anterior o decide que la petición debe rechazarse, los plazos para recurrir (quince días) se cuentan desde la intimación del nuevo decreto (cann. 1735 y 1737$)^{57}$.

b) Si la petición no ha sido resuelta en el plazo de treinta días, es decir, el autor del acto no ha tomado durante este tiempo decisión alguna, el plazo de quince días se contará desde el trigésimo de su presentación (cann. 1735 y 1737).

Conviene recordar que, tratándose de un plazo perentorio fijado en días útiles ${ }^{58}$, una vez transcurrido el mismo, el interesado, si conocía y podía recurrir, pierde la posibilidad de interponer el recurso jerárqui$\mathrm{co}^{59}$, y el acto se convierte en firme ${ }^{60}$.

${ }^{56}$ En el can. 1735 CIC se dispone: «Si el autor del decreto, en el plazo de treinta días desde que recibió la petición mencionada en el c. 1734, intima un nuevo decreto por el que corrige el anterior o bien decide que la petición debe rechazarse, los plazos para recurrir se cuentan desde la intimación del nuevo decreto; pero si en el plazo de treinta días no ha tomado ninguna decisión, el plazo se cuenta desde el día trigésimo».

57 Como señala Alejandro Bunge: «La intimación es un acto de la autoridad que consiste en comunicar al interesado el contenido del decreto. Para que pueda exigirse el cumplimiento de un decreto singular, la intimación debe constar por escrito en un documento legítimo. Esta determinación no es una norma irritante, y por lo tanto no es necesario para la validez de la intimación y la eficacia singular que ésta conste por escrito, sino sólo para que se pueda exigir su cumplimiento. Por eso, aquél que conociendo la existencia de un decreto singular se considera afectado por sus determinaciones, si se le acusa de no cumplirlas, no podrá defenderse diciendo que no las acatará mientras no sea legítimamente notificado y no se le puede exigir el cumplimiento. Solo la constancia escrita de la legítima notificación podrá permitir a la autoridad exigir el cumplimiento de las determinaciones de un decreto singular». Alejandro Bunge, Las claves del Código: el Libro I del Código de Derecho Canónico (Buenos Aires: San Benito, 2006), 137.

58 Al respecto es de aplicación lo previsto en los cann. 201-203 CIC.

59 Vid. Baura, "Ricorsi Gerachici”, 121.

${ }^{60}$ Si la ejecución del acto había quedado en suspenso, en aplicación del can. 1734 $\S 1 \mathrm{CIC}$, podrá ejecutarse a partir de esa fecha. 


\subsection{ANTE QUIÉN SE PRESENTA}

La segunda de las cuestiones planteadas es la referida a la autoridad ante la que el recurso debe presentarse. Al respecto, en el canon $1737 \S 1$ se dispone que el recurso puede interponerse ante el mismo autor del acto, quien inmediatamente, eum statim, dice el texto latino, debe transmitirlo al competente superior jerárquico para su pronta sustanciación y resolución ${ }^{61}$.

En consecuencia, es posible concluir que el recurso administrativo puede interponerse a elección del recurrente:

a) Directamente ante el superior jerárquico que debe decidir.

b) Ante la misma autoridad que dictó el acto que ahora se recurre, la cual deberá transmitirlo inmediatamente al superior jerárquico que corresponda.

Ya escoja el recurrente una u otra opción, debe quedar claro que, a partir del momento de la presentación del recurso ${ }^{62}$, el conocimiento del procedimiento, salvo el traslado señalado en el caso comentado, escapa de la competencia del superior del que emanó el acto recurrido, comenzando la de su superior jerárquico, es decir, la del órgano ad quem ${ }^{63}$. Sobre este punto, Jorge Miras puntualiza que «el autor del acto recurrido podría siempre continuar intentando vías de solución distintas del recurso, como sabemos, (c. 1733, párrafo tercero), pero "simultánea y paralelamente a su sustanciación", es decir, sin congelar la tramitación del recurso, que debe ser en todo caso "inmediata" por su parte» ${ }^{64}$. En cualquier caso, es digna de alabanza la solución adoptada por el legislador, admitiendo las dos posibilidades expuestas, dado que facilita verdaderamente al interesado la presentación del recurso y, en consecuencia, la protección jurídica de sus derechos e intereses legítimos.

${ }^{61}$ En el can. 1737 §1 CIC se dispone: «Quien se considera perjudicado por un decreto, puede recurrir por cualquier motivo justo al superior jerárquico de quien emitió el decreto, el recurso puede interponerse ante el mismo autor del decreto, quien inmediatamente debe transmitirlo al competente superior jerárquico».

62 Tal y como afirma Eudardo Labandeira: «Ninguna razón excusaría la retención del recurso por parte de la autoridad inferior». Labandeira, "Tratado de Derecho Administrativo Canónico”, 439.

63 Lamberto de Echevarría insiste en que «en la práctica, en casi todos los casos» el superior jerárquico encargado de resolver son los organismos de la curia romana. Pero, la práctica indica que esta afirmación no es del todo exacta. Vid. De Echevarría, sub. can. 1737 y can. 1738, 839.

${ }^{64}$ Miras, “Compendio de derecho administrativo canónico”, 283-284. 
Resta comentar un aspecto concreto que la autoridad que recibe el recurso jerárquico no podrá dejar de tener presente. Como en su momento se expuso, en la mayoría de los supuestos la presentación de un recurso deberá precederse de la petición de enmienda o revocación del acto a la autoridad que lo dictó ${ }^{65}$. Pues bien, en aquellos casos en que sea preceptiva dicha petición, si el recurso jerárquico se presenta sin haberse realizado, el superior competente para resolver, después de hacer las averiguaciones y comprobaciones necesarias ante la autoridad autora del acto, lo deberá rechazar. Tales comprobaciones son necesarias, ya que la práctica enseña que no siempre es fácil verificar los presupuestos necesarios para la admisión del recurso. Es más, cada caso precisa indagaciones específicas sobre la legitimación y sobre los plazos de notificación, destinadas a cerciorarse de cuándo ha conocido el interesado el decreto. Tampoco la fijación precisa de los términos temporales es cosa exenta de complejidad, dado que no siempre las autoridades eclesiales informan a los interesados de las posibilidades jurídicas que tienen para recurrir, o bien, la redacción del decreto cuestionado no es clara o la forma que revista induce a duda.

Alguna complejidad más se presenta en el caso comentado cuando el autor del acto es quien recibe el recurso. Al respecto caben dos soluciones. La primera consiste en estimar que esta labor de comprobación debe realizarse de igual forma que lo haría el superior jerárquico competente para resolver. La segunda implica entender que el autor del acto recurrido debe limitar su intervención a dar traslado material del recurso al superior jerárquico, quien decidirá sobre la admisión o no del recurso sobre la base de la omisión o no de la petición previa de enmienda o revocación. Dadas las posibles circunstancias concurrentes, la segunda de las soluciones expuestas parece más correcta. Una vez subsanada, en su caso, la falta observada, es decir, la carencia de petición previa de revocación o enmienda cuando sea preceptiva, siempre que no haya transcurrido el plazo previsto, y tras su debida resolución conforme a lo prescrito en la norma, entonces podrá el interesado presentar nuevamente el recurso jerárquico. Lo que podrá hacer, como se ha dicho, ante el autor del acto cuestionado o ante el superior jerárquico encargado de conocer.

${ }^{65}$ Cfr. can. 1734 CIC. 


\subsection{INADMISIÓN Y SUBSANACIÓN DE DEFECTOS FORMALES}

Otro tanto cabe matizar respecto de aquellos supuestos en los que el escrito del recurso adolece de alguna deficiencia grave, como puede ser que la autoridad ante la que se presenta carece de competencia para resolver $^{66}$, es decir, cuando en realidad no es el superior jerárquico, o consta con certeza que el recurrente no disfruta de suficiente capacidad porque no está en el pleno ejercicio de sus derechos ${ }^{67}$. Asimismo, cuando se constata que el recurrente carece de suficiente legitimidad, se trata de un acto no susceptible de recurso, o bien, porque haya transcurrido el plazo para su interposición. En estos casos cabe la inadmisión, si bien el rechazo del recurso deberá hacerse por decreto razonado. Más adelante se volverá a tratar este asunto.

Más discutible es la inadmisión del recurso por carecer manifiestamente de fundamento. En principio, la inadmisión no debe basarse en su contenido, es decir, en la pretensión del recurrente, sus motivos, ni tampoco en la carencia de constatación probatoria. Estos elementos serán valorados por el superior jerárquico a la hora de resolver el recurso de conformidad a lo previsto en el canon $1739^{68}$. Ciertamente, en el canon $1737 \S 1$ se prevé que quien se considera perjudicado por un decreto, puede recurrir "por cualquier motivo justo» al superior jerárquico, lo que lleva a Jorge Miras a estimar que «esa expresión amplia solo excluye los recursos que se presenten sin motivo alguno, o por un motivo que no pueda considerarse "justo" ${ }^{69}$. La ausencia completa de motivo podría implicar la inadmisión, dado que se requiere la alegación de alguno, pero la determinación de la justeza del motivo, parece más conveniente que el superior jerárquico la realice en el momento de la resolución.

Por el contrario, si se está ante defectos que es posible subsanar, el recurrente podrá presentar un nuevo recurso correctamente redactado.

${ }^{66}$ En estos casos se produce una incompetencia funcional para resolver el recurso jerárquico presentado.

67 Cfr. cann. 97-99 CIC.

${ }^{68}$ En el can. 1739 CIC se dispone: «Según lo requiera el caso, el Superior que resuelve el recurso puede no sólo confirmar o declarar nulo el decreto, sino también rescindirlo o revocarlo o, si lo juzga más conveniente, corregirlo, sustituirlo por otro o abrogarlo».

69 Jorge Miras, "Recurso jerárquico", en Diccionario General de Derecho Canónico, v. IV, eds. y coords. Javier Otaduy, Antonio Viana y Joaquín Sedano (Pamplona: Thomson Reuters Aranzadi, 2012), 777. 
Aquí, el tratamiento debe ser similar al que está previsto para los escritos de demanda en el canon $1505 \S 3$.

\section{EFECTOS}

La interposición de un recurso administrativo en su debido tiempo y forma implica el inicio de su sustanciación ante el superior jerárquico. Pero, al margen de esta consecuencia, que evidentemente es esencial y principal, también se producen otros variados efectos que no dejan de ser importantes, y merecen, en consecuencia, una especial atención. En la exposición de los efectos producidos con la interposición del recurso es conveniente distinguir entre tres categorías distintas: en primer lugar, aquellos que tienen como ámbito el propio acto administrativo; en segundo lugar, los que producen consecuencias para los sujetos intervinientes en su tramitación, es decir, para el recurrente, recurrido y el órgano encargado de resolver (superior jerárquico); finalmente, y en tercer lugar, deben señalarse otros efectos singulares que afectan a diferentes elementos de la relación jurídica establecida, y que tienen lugar también con ocasión de la interposición del recurso jerárquico.

\subsection{SOBRE EL ACTO}

Los efectos que la presentación del recurso jerárquico produce sobre el mismo acto son la pendencia del asunto, la suspensión de ciertos plazos y, en muchos casos, la suspensión de su ejecución. Conviene analizarlos por separado.

a) Pendencia del asunto. Asiste la razón a Eduardo Labandeira cuando afirma que una consecuencia inmediata y automática de la presentación del recurso jerárquico es que el acto administrativo deja de ser íntegro, dando comienzo la pendencia del asunto litigioso. A partir de entonces el acto se encuentra sometido jurídicamente a litigio y, por ello, su legalidad u oportunidad es cuestionada ante el superior jerárquico competente para decidir ${ }^{70}$. La consecuencia

${ }^{70}$ Eduardo Labandeira, "Manual de Derecho Canónico”, 755. No obstante, conviene recordar que existen dos posiciones doctrinales en torno a la consideración indicada. Por un lado, se encuentran aquellos autores que estiman que el acto 
es inmediata, puesto que, como afirma el mismo autor, el hecho de que el acto se convierta en cosa litigiosa significa no solo que queda pendiente de revisión por el superior ad quem, sino también que permanece abierta la posibilidad de acceder a posteriores instancias administrativas o jurisdiccionales ${ }^{71}$.

b) Suspensión de los plazos. Los demás efectos se producen en cadena, y así, la situación de pendencia o litigio motiva la inmediata interrupción de aquellos plazos fatales que implique el contenido dispositivo del acto administrativo recurrido, o lo que es igual, los plazos determinados por la ley para la perención o caducidad de los derechos ${ }^{72}$.

c) Suspensión de la ejecución. Al mismo tiempo se produce otro efecto igualmente importante, porque la interposición de un recurso jerárquico puede dar lugar, en determinados supuestos, a la suspensión de la ejecución del acto recurrido, circunstancia que adquiere una importancia muy destacable en su tramitación. La consecuencia es que en estos supuestos el superior del que ha emanado el acto impugnado de momento no puede ejecutarlo.

Si los dos primeros efectos señalados son claros, el último motiva algunas reflexiones. Efectivamente, la posible suspensión del acto con ocasión de un recurso jerárquico resulta lógica y prudente, puesto que procura evitar eventuales perjuicios derivados de su ejecución y la correlativa dificultad de repararlos cuando el superior resuelve más tarde a favor del recurrente ${ }^{73}$. Por ello, cabe concluir que el fundamento de

recurrido es ya perfecto y definitivo (lo que no quiere decir que sea firme). Es más, la perfección del acto es presupuesto necesario para la interposición del recurso. Por otro lado, están aquellos otros que entienden que el acto impugnado es aún un acto en formación, ya que, precisamente, puede ser objeto de un recurso jerárquico. De esta manera, se estaría ante un único procedimiento administrativo, que englobaría tanto la elaboración del acto como la resolución de su impugnación por el superior competente. Aunque se refiere a la legislación del anterior CIC, puede consultarse Corrado Bernardini, "Commento allo schema "De procedura administrativa", Apollinaris 45 (1972): 133ss; y Pio Cipriotti, "Stato attuale e propescttive della giustizia ammnistrativa canonica”, Monitor 98 (1974): 357.

71 Eduardo Labandeira, "Tratado de Derecho Administrativo Canónico", 440.

72 Cfr. can. 1465 §1 CIC.

${ }^{73}$ Respecto a la suspensión de los actos administrativos con ocasión de la interposición de un recurso jerárquico, Eduardo Baura estima que la necesidad de evitar la producción de daños irreparables al administrado debe ser considerada, por un lado, pero, por otro, está la protección del bien público, que a veces requiere la 
esta suspensión en ciertas circunstancias es contundente, y lo es hasta el punto de que llega a enervar un principio fundamental de todo ordenamiento administrativo, como es la presunción de legitimidad y la consiguiente ejecutoriedad que asiste a sus actos ${ }^{74}$. No puede extrañar, pues, que el derecho de la Iglesia admita esta posibilidad, que en todo caso tendrá carácter provisional ${ }^{75}$.

La doctrina señala que, a la vista de la regulación contenida en el código, la regla general es que la interposición del recurso jerárquico solo produce un efecto devolutivo ${ }^{76}$, pero no suspensivo ${ }^{77}$. Así lo hace, por ejemplo, Jorge Miras, cuando afirma que: «Si en el ámbito judicial la apelación, como regla general, suspende siempre la ejecución de la sentencia, en cambio, en el recurso administrativo la norma es la contraria. A pesar del orden en que se expresa el c. 1736, puede decirse que, por regla general, el recurso jerárquico "sólo produce efecto devolutivo", salvo en algunos casos expresamente determinados por la ley» ${ }^{78}$. Resulta evidente que esta afirmación es correcta, porque no deja de ser cierto que el recurso jerárquico no suspende la ejecución del acto recurrido en todos los $\operatorname{casos}^{79}$. Sin embargo, la rotundidad de la aseveración precedente no

ejecución inmediata de ciertas medidas que no pueden ser bloqueadas por la reclamación de los individuos. Baura, "Ricorsi Gerachici”, 122.

${ }^{74}$ Sobre la presunción de validez escribe Alberto Bernárdez Cantón: «El vigente Código, sin conexión con el anterior, la formula en estos términos: "Se presume válido el acto jurídico debidamente realizado en cuanto a sus elementos externos" (c. 124, 2). Fácilmente se alcanza que es una medida de certeza o seguridad jurídica por cuanto permite tener por válidos los actos realizados correctamente [...]. Por descontado que es una presunción que puede ceder ante la realidad mediante prueba en contrario (iuris tantum)». Alberto Bernárdez Cantón, Parte general de Derecho Canónico (Madrid: Centro de Estudios Ramón Areces, 1990), 196.

${ }^{75}$ El carácter provisional se reseña expresamente en dos ocasiones: can. $1736 \S 1$ $\mathrm{y} \S 4$.

${ }^{76}$ El efecto devolutivo hace referencia a que la tramitación y resolución del recurso corresponde al órgano administrativo superior al que dictó la resolución recurrida. Vid. Valentín Cortes et alii, Derecho Procesal. t. I, v. II. Proceso Civil (2), 5. a ed. (Valencia: Tirant lo Blanch 1990), 27.

77 Cuando se produce el efecto suspensivo determina la imposibilidad de ejecutar la resolución recurrida. Ibidem, 27.

78 Miras, "Compendio de derecho administrativo canónico" (Pamplona: Eunsa, 2001), 285.

${ }^{79}$ Eduardo Labandeira escribe: «por regla general (la interposición del recurso) solo tiene efecto devolutivo, aunque las excepciones - recurso suspensivo- sean de notable importancia». Labandeira, sub. can. 1737, 1041. 
debe confundir, puesto que, en la práctica, y también con fundamento en las diferentes previsiones del código, en la mayoría de los casos planteados la interposición del recurso jerárquico implica la suspensión del acto recurrido, si bien, salvo en supuestos excepcionales, deberá mediar la decisión del superior competente acordando este efecto. Es decir, si se tienen en cuenta los supuestos en los que la norma canónica prevé expresamente la suspensión de la ejecución del acto recurrido, junto a la posibilidad de que en el resto de los casos el superior encargado de resolver puede acordarla, no es temerario afirmar que, en realidad, la regla general «de hecho» sea la suspensión, ya que tan solo en ocasiones muy especiales se denegará este efecto.

El régimen de la suspensión de los actos administrativos recurridos previstos en el Código de Derecho Canónico es ciertamente complejo, exigiendo una labor de sistematización sobre la base de distinguir los supuestos de suspensión automática y aquellos otros en que los que la suspensión no se produce automáticamente por ministerio de la ley. De este modo caben las siguientes posibilidades:

a) Suspensión automática. En algunos supuestos excepcionales la suspensión viene acordada directamente por la norma canónica. Es un efecto suspensivo automático y que actúa ope legis (ipso iure, en la terminología latina del código) desde la presentación, no ya del recurso, sino incluso de la petición previa de enmienda o revocación, como se desprende de la previsión del canon 1736 §1: «Cuando en una materia el recurso jerárquico suspende la ejecución de un decreto, la petición del c. 1734 produce idéntico efecto ${ }^{80}$. Se trata de asuntos verdaderamente graves, cuyo tratamiento exige la máxima prudencia. Como puede apreciarse, esta solución resulta completamente lógica, pues carecería de sentido dar un tratamiento contradictorio al recurso que se ha interpuesto y a la petición previa de revocación o enmienda previa.

b) Suspensión acordada antes de la presentación del recurso. Dispone el canon 1734 \$1 que «Antes de interponer recurso, el interesado debe solicitar a su autor por escrito la revocación o enmienda del decreto; hecha esa petición se considera solicitada automáticamente también la suspensión de la ejecución del decreto». Es decir, presentada la petición

80 De este modo, la suspensión automática está prevista en los siguientes cánones: can. 143 CIC (extinción de la potestad ordinaria); can. 700 CIC (expulsión de religiosos); can. 1353 CIC (decretos penales); can. 1747 CIC (remoción de párrocos) y can. 1752 CIC (traslado de párrocos). 
previa de enmienda o revocación del acto administrativo, en los supuestos en que se exige, se entiende automáticamente solicitada también la suspensión de su ejecución.

Desde la presentación de la petición previa comenzará a contar un plazo de diez días para que el autor del acto decida solo respecto a la suspensión, pudiendo concederla o denegarla según su criterio. Así se desprende de la redacción del canon 1736 §2: «En los demás casos si, en el plazo de diez días después de recibida la petición del c. 1734, el autor del decreto no decide suspender la ejecución del mismo, puede pedirse provisionalmente esa suspensión a su Superior jerárquico, que tiene facultad para otorgarla sólo por causas graves y cuidando siempre de que no sufra detrimento el bien de las almas». Por consiguiente, una vez transcurrido el plazo de diez días sin que el superior se haya pronunciado, la suspensión se entenderá denegada, en cuyo caso el interesado puede solicitarla al superior jerárquico, o lo que es igual, a la autoridad eclesial que habrá de resolver, en su caso, el posterior recurso. Este superior, podrá, en consecuencia, conceder provisionalmente la suspensión del acto antes incluso de la interposición del recurso, si bien, solo puede hacerlo por causas graves, cuya valoración le corresponde, y cuidando de que no sufra detrimento el bien de las almas.

No deja de llamar la atención que la suspensión acordada por el superior jerárquico que ha de resolver se encuentre acotada, dado que en el canon 1736 §2 se prevé que solo podrá acordarla "por causas graves y cuidando siempre de que no sufra el bien de las almas». Estas circunstancias, por el contrario, no aparecen cuando en el código se regula la suspensión acordada por el propio autor del acto en el canon 1734, lo que puede dar lugar a considerar que el margen de discrecionalidad de que dispone a la hora de acordar la suspensión es mayor que el atribuido al superior jerárquico que deberá resolver ${ }^{81}$.

En todo caso, las previsiones comentadas se completan con la del canon $1736 \S 3$, puesto que una vez interpuesto el recurso, si se concedió la suspensión provisional en la fase previa, el superior jerárquico ante quien se recurre decidirá sobre la confirmación o revocación de

${ }^{81}$ No debe excluirse la posibilidad de que la autoridad competente haga depender la suspensión de la adopción de las medidas cautelares que sean necesarias para la protección del interés público o de terceros y la propia eficacia de la resolución o el acto impugnado. Al respecto, vid. Ramón Parada Vázquez, Derecho Administrativo I. Parte General, 13. ${ }^{a}$ ed. (Madrid: Marcial Pons, 2002), 674. 
la suspensión anteriormente concedida por la parte recurrida o, en su caso, por el mismo superior: «Cuando se ha suspendido la ejecución de un decreto de acuerdo con el §2, si después se interpone el recurso debe confirmarse o revocarse, en conformidad con el c. $1737 \S 3 »^{82}$.

c) Concesión posterior, acordada una vez presentado el recurso. Una vez presentado el recurso sin que en la fase previa se hubiera acordado la suspensión, el superior encargado de resolverlo podrá acordarla ahora, concurriendo causa grave y cuidando de que se evite todo perjuicio al bien de las almas, tal y como se establece en el canon 1737 §3: «Aun en los casos en que el recurso no suspenda "ipso iure" la ejecución del decreto, ni se haya decretado la suspensión según el c. 1736 §2, puede el Superior por causa grave mandar que se suspensa la ejecución, con tal que se evite todo perjuicio al bien de las almas».

Podría concurrir un supuesto no contemplado específicamente en el Código de Derecho Canónico. Dada la claridad con que se expone, así como lo acertado de su tratamiento, resulta conveniente citar literalmente la opinión de Jorge Miras: «No se regulan expresamente en el Código las peculiaridades del "iter" que ha de seguir la suspensión en los casos en que no se exige la petición previa al recurso. A nuestro juicio, cabría también en estos supuestos - si el interesado lo estima necesario- comenzar el trámite de la suspensión antes de la interposición del recurso, [...] es decir, presentando en primer lugar al superior jerárquico la solicitud de suspensión provisional, que podría otorgarse y ser confirmada o revocada una vez presentado el recurso propiamente dicho. Esta interpretación nos parece acorde con la finalidad para la que se ha previsto la posibilidad de suspender la ejecución del acto administrativo, que sigue estando vigente en esos supuestos de recurso directo al superior». ${ }^{83}$ Otra posibilidad en estos casos es la de interponer el recurso en el plazo de quince días desde que el decreto ha sido intimado, solicitando al superior jerárquico en el mismo escrito la suspensión. Resta añadir, que en aquellos casos excepcionales en los que la suspensión viene acordada directamente por la norma canónica, su efecto es automático y actúa desde la solución propuesta por el autor citado o bien desde el mismo momento de la presentación del recurso.

${ }^{82}$ Manuel Jesús Arroba Conde escribe: "El recurso exige del superior, confirmar o revocar la suspensión, si esta hubiera sido concedida provisionalmente”. Arroba, sub. can. 1737, 745.

${ }^{83}$ Miras, “Compendio de derecho administrativo canónico”, 287. 
Las previsiones legales que se han expuesto antes sobre la suspensión del acto administrativo implican que el Código de Derecho Canónico atribuye al superior que resolverá el recurso amplia potestad para determinar lo más conveniente en el supuesto concreto que se le ha planteado, atendiendo a la concurrencia «de causa grave y cuidando siempre de que no sufra detrimento el bien de las almas ${ }^{84}$. En todo caso, siempre deberá respetarse la suspensión que haya sido impuesta por la ley, ope legis, y sobre la que no cabe discusión alguna. Al respecto, Lamberto de Echevarría estima que: «Queda claro, por tanto, que el Código concede al superior una amplia potestad para determinar lo más conveniente en el caso, aunque deberá respetar la suspensión que haya sido contraída "ipso iure" ${ }^{85}$.

$\mathrm{Al}$ margen de las previsiones legales comentadas, es evidente que en toda la materia relacionada con la suspensión de la ejecución de los actos administrativos recurridos debe enmarcarse dentro de los límites característicos de la actividad administrativa, en cuanto ejercicio inmediato de la función de gobierno que persigue de oficio el bien público eclesial. Y como antes se dijo, aun cuando la interposición del recurso produce exclusivamente efecto devolutivo y no suspensivo, la normativa del código parece inducir también al suspensivo, pues la posibilidad de suspensión del acto recurrido aparece en cascada desde el canon 1734 §1 hasta el canon 1736 §3: suspensión ope legis (c. 1736 §1); solicitud de suspensión al autor del acto junto a la petición de su revocación o enmienda (c. 1734 §1); posible solicitud de suspensión al superior jerárquico antes de interponer el recurso (c. 1736 §2); posible solicitud de suspensión al superior jerárquico una vez interpuesto el recurso (c. 1736 $\S 3)^{86}$. Es más, como acertadamente señala Eduardo Labandeira, incluso en aquellos casos en que no se disponga por la norma o acuerde el su-

${ }^{84}$ Cfr. can. 1736 §2 y can. 1737 §3 CIC.

${ }^{85}$ De Echevarría, sub. c. 1737, 839. Por su parte, Pio Vito Pinto vincula la concesión de la suspensión decidida al margen de los supuestos ope legis, con la consideración del bien común, quedando su valoración pro sua conscientia de la autoridad eclesiástica competente. Ahora bien, el concepto del bien de las almas, al que se refiere el texto del canon, no coincide plenamente con el de bien común. Pinto, "El recurso jerárquico", 52.

${ }^{86}$ Refiriéndose a la carencia de efecto devolutivo del recurso jerárquico, Jorge Miras afirma que «esta norma protege la acción de gobierno, dirigida al bien público, del bloqueo que supondría la eficacia suspensiva automática de cualquier recurso. Sin embargo, muchas veces será prudente suspender el acto hasta que se resuelva la 
perior competente la suspensión «habrá de evitarse que la ejecución del acto sea irreversible, de tal manera que se convierta en algo inútil el recurso ${ }^{87}$. Una reflexión más a favor de que la suspensión debe prevalecer en muchos casos sobre la ejecución hasta la resolución definitiva del recurso interpuesto.

Finalmente, cabe reseñar que las disposiciones del Código de Derecho Canónico sobre la suspensión del acto objeto del recurso se cierran con lo dispuesto en el canon $1736 \S 4$ : «Si no se interpone recurso contra el decreto dentro del plazo prescrito, cesa por eso mismo la suspensión de la ejecución decidida provisionalmente de acuerdo con los $\$ \$ 1$ o 2 ». Se trata de una lógica consecuencia, ya que, si no se interpone recurso contra el acto dentro del plazo prescrito, desaparece la razón que la fundamenta y cesa por eso mismo la suspensión de la ejecución decidida provisionalmente de acuerdo con los párrafos primero o segundo del mismo canon y, consiguientemente, podrá ejecutarse el acto administrativo sin más dilaciones. Aunque en el código no se prevea expresamente, la suspensión provisional también cesa una vez que la posibilidad de seguir interponiendo recursos jerárquicos contra el acto administrativo queda agotada ${ }^{88}$.

\subsection{Sobre LOS SUJETOS}

La interposición del recurso jerárquico produce efectos inmediatos no solo en el acto que constituye su objeto, sino que también sobre los sujetos intervinientes en el procedimiento y, lógicamente, en el superior jerárquico encargado de resolver.

a) Sujetos recurrente y recurrido. El perjudicado por el acto impugnado adquiere la condición formal de recurrente, y la autoridad de la que ha emanado el acto recurrido será desde entonces el sujeto recurrido, también denominada «resistente». Ambas situaciones generan los derechos y las obligaciones que corresponden a los sujetos intervinientes durante la tramitación del procedimiento. Así, por ejemplo, el derecho a la asistencia de abogado y procurador, o la obligación que

impugnación, por la delicadeza de la materia o por la difícil reparación de los efectos que produciría entretanto». Miras, "Recurso jerárquico", 778.

87 Eduardo Labandeira, "Tratado de Derecho Canónico", 442.

88 Vid. Labandeira, sub. c. 1736, 1040. 
pesa sobre el recurrente de comparecer personalmente ante el superior jerárquico encargado de resolver el recurso para ser interrogado ${ }^{89}$. No debe olvidarse el deber que tiene el autor del acto de transmitir inmediatamente el recurso interpuesto al competente superior jerárquico ${ }^{90}$.

La cuestión de si el acto impugnado resulta inmutable para su autor desde el momento en que se interpone el recurso, parece resuelta a favor de estimar lo contrario. La función tutelar de los intereses generales que corresponde a la Administración eclesiástica puede ajustar sus decisiones a las necesidades concretas que se plantean, incluyendo la ponderación de nuevos elementos que recomiendan una nueva decisión. Por otro lado, la voluntad del legislador es que se eviten los conflictos entre el fiel y el autor del acto, previéndose en los cánones 1733-1734 diversas soluciones tendentes a lograr soluciones equitativas de común acuerdo, que podrán alcanzarse a lo largo de la tramitación del procedimiento.

b) El superior jerárquico ${ }^{91}$. De igual manera, también para el superior que decide el recurso se originan deberes, destacando como principal la obligación irrenunciable de tramitar y resolver con diligencia ${ }^{92}$ y en el plazo debido el recurso administrativo interpuesto legítimamente $^{93}$. Este plazo está previsto en el canon 57 §1: «Cuando la ley prescribe que se emita un decreto, o cuando el interesado presenta legítimamente una petición o recurso para obtener un decreto, la autoridad competente debe proveer dentro de los tres meses que siguen a la recepción de la petición o del recurso, a no ser que la ley prescriba otro

${ }^{89}$ Cfr. can. 1738 CIC.

${ }^{90}$ En el supuesto de que el recurrente haya optado por interponer el recurso ante el mismo autor del acto. Cfr. can. 1737 §1 CIC.

${ }^{91}$ La interposición del recurso jerárquico instaura, o al menos, actualiza la competencia del superior. Precisamente en esta situación consiste el efecto devolutivo que implica. Vid. Jorque Miras, sub. can. 1737, en Comentario Exegético al Código de Derecho Canónico, vol. IV/2, coords. Ángel Marzoa, Jorge Miras y Rafael Rodríguez Ocaña (Pamplona: EUNSA), 2153.

92 Corresponde al superior una actividad impulsora y ordenadora del procedimiento, evitando demoras indebidas.

${ }_{93}$ Cfr. can. 57 CIC. Eduardo Labandeira entiende que se trata de un derecho y un deber del superior competente de resolver: «respecto del superior ad quem, se produce el efecto devolutivo, lo que implica no sólo la facultad sino también obligación de pronunciarse acerca del recurso». Labandeira, "Tratado de Derecho Canónico", 440. 
plazo». Por consiguiente, el superior jerárquico dispone de un plazo de tres meses para resolver el recurso recibido ${ }^{94}$.

Quedan a salvo las situaciones en las que el superior que recibe el recurso lo rechaza. Estos supuestos generalmente responden a que dicho superior aprecia su manifiesta falta de competencia para resolver. No obstante, también en estas circunstancias se mantiene la obligación de proveer por escrito y constatando expresamente los motivos de la decisión ${ }^{95}$. Es evidente que la inadmisión del recurso por la causa apuntada, o por cualquier otra, podrá ser recurrida, a su vez, ante el superior correspondiente, siempre que el recurrente se mantenga en la creencia de que ha interpuesto el recurso ante el órgano ad quem competente.

\subsection{OtRos EFECTOS}

La interposición de un recurso jerárquico produce efectos esencialmente sobre el acto administrativo cuestionado. También sobre los sujetos de la relación jurídica que se establece, es decir, sobre el recurrente y el recurrido, así como sobre el superior jerárquico que ha de resolver. Pero en determinados preceptos del Código de Derecho Canónico también se prevé la producción de otros posibles efectos con ocasión de la interposición de un recurso jerárquico, y que afectan a singulares instituciones jurídicas, cuyo carácter particular no exime de algún comentario.

Uno de estos efectos está contemplado en el canon 143, precepto en el que se establece que la potestad ordinaria se extingue por la pérdida del oficio al que va aneja. Sin embargo, esta previsión se completa con lo establecido en el párrafo segundo del referido precepto, ya que a no ser que el derecho disponga otra cosa, la potestad ordinaria queda suspendida cuando legítimamente se apela o se interpone recurso contra la privación o remoción del oficio ${ }^{96}$. Es fácil percatarse de que el legislador afirma que el recurso no extingue, pero sí suspende la potestad or-

${ }_{94}$ Cfr. cann. 200-203 CIC.

95 Cfr. cann. 51 y 57 CIC.

96 En el can. 143 CIC se dispone: «\$1. La potestad ordinaria se extingue por la pérdida del oficio al que va aneja. §2. A no ser que el derecho disponga otra cosa, la potestad ordinaria queda suspendida cuando legítimamente se apela o se interpone recurso contra la privación o remoción del oficio». 
dinaria derivada del oficio. Por tanto, durante ese periodo, la potestad estará en potencia, no en acto y, en consecuencia, queda suspendida en cuanto al ejercicio, siendo en caso contrario nulo todo lo que se haga. Según opinión de Benito Gangoiti, el legislador, contra la regla jurídica lite pendente nihil innovetur, mientras esté pendiente la causa, debía haber optado por prevalecer la regla general del efecto suspensivo del recurso jerárquico, mientras no constase lo contrario. Sin embargo, en el canon comentado queda establecida la regla contraria, que en opinión del citado autor, produce "grandes destrozos en el mundo de la justicia administrativa o no administrativa ${ }^{97}$.

Similar consecuencia conlleva la interposición de un recurso jerárquico en el supuesto contemplado en los cánones 1747 y 1752. Efectivamente, según el canon 1747 §3, relativo a la remoción de los párrocos, «mientras esté pendiente el recurso contra el decreto de remoción, el Obispo no puede nombrar nuevo párroco, sino que debe proveer interinamente por medio de un administrador parroquial». Por su parte, según el canon 1752, se producirá igual efecto en el caso del traslado de los párrocos, siendo también de aplicación la previsión contenida en el canon 1747, si bien, guardando la equidad canónica y teniendo en cuenta la salvación de las almas, que debe ser siempre la ley suprema de la Iglesia $^{98}$.

\section{CONCLUSIONES}

Partiendo de la idea de que el recurso jerárquico es un medio más de la justicia administrativa en el seno de la Iglesia, que permite impugnar ciertos actos de la autoridad en la misma vía procedimental en la que se han producido, en el Código de Derecho Canónico se regula el procedimiento a seguir en los cánones 1732 al 1739.

La referida regulación es sucinta, limitándose a describir sus elementos más sobresalientes. De este modo, las previsiones sobre los requisitos

97 Benito Gangoiti, sub. can. 143, en Código de Derecho Canónico. Edición bilingüe, fuentes y comentarios de todos los cánones, dir. Antonio Benlloch Poveda (Valencia: EDICEP, 1993), 93.

${ }_{98}$ En el can. 1752 CIC se dispone: «En las causas de traslado, es de aplicación el c. 1747, guardando la equidad canónica y teniendo en cuenta la salvación de las almas que debe ser siempre la ley suprema de la Iglesia». 
necesarios para una válida presentación del recurso jerárquico son más bien escuetas, debiendo completarse mediante el recurso a la analogía y elaboración doctrinal. Otro tanto sucede con los efectos que dicha presentación produce sobre el acto recurrido y los sujetos que intervienen en su impugnación administrativa.

En cuanto a los requisitos, cabe clasificarlos entre subjetivos, objetivos, jurídicos, petitorios y otros. Y respecto a los efectos producidos sobre el acto recurrido son: pendencia, suspensión de los plazos y suspensión de la ejecución. Asimismo, caben otros diferentes y acotados efectos.

La eventual intervención de abogado y procurador asistiendo al recurrente y, en su caso, al recurrido, debe entenderse, no solo como una garantía de buen hacer técnico en materia tan compleja como es el derecho administrativo de la Iglesia, sino también como exponente del derecho de defensa que asiste a todos los fieles.

En todo caso, la incidencia de los requisitos y efectos producidos con la interposición del recurso jerárquico es grande, recayendo de manera decisiva en el desarrollo posterior del procedimiento.

\section{REFERENCIAS}

Baura, Eduardo. "I ricorsi gerarchici". En Il diritto nel mistero della Chiesa: Prassi amministrativa e procedure speciali, editado por Gruppo Italiano docenti di diritto canonico, 115-134. Città del Vaticano: Pontificium Institutum Utrusque Iuris, 2014.

Beal, Jonh P. "Hierchical Recourse: Procedures at local level”. CLSA Proceedings 62 (2000): 93-106.

Bernárdez Cantón, Alberto. Parte general de Derecho Canónico. Madrid: Centro de Estudios Ramón Areces, 1990.

Bernardini, Corrado. "Commento allo schema De procedura administrativa”. Apollinaris 45 (1972): 126-136.

Bunge, Alejandro. Las claves del Código: el Libro I del Código de Derecho Canónico. Buenos Aires: San Benito, 2006.

Cipriotti, Pio. "Stato attuale e propescttive della giustizia ammnistrativa canonica". Monitor 98 (1974): 354-361.

Cortes, Valentín, et al. Derecho Procesal. T. I, vol. 2, Proceso Civil (2). 5. ${ }^{\text {a }}$ ed. Valencia: Tirant lo Blanch, 1990. 
Entrena Cuesta, Rafael. Curso de Derecho Administrativo. Vol. I/I. 13. ${ }^{a}$ ed. Madrid: Editorial Tecnos, 1999.

García Faílde, Juan José. Nuevo Derecho Procesal Canónico. Salamanca: Ediciones UPSA, 1995.

Grocholewski, Zenon. "Atti e ricorsi amministrativi”. Apollinaris 57 (1984): 258-279.

—. "Treinta años de justicia administrativa canónica. Balance y perspectivas". Fidelium Iura 8 (1998): 267-307.

-. "Il sistema dei recorsi e la giurisdizione dei tribunal admministrativi". En I principi per la revisione del códice di diritto canonico. La recezione giuridica del Concilio Vaticano II, a cura di Javier Canosa, 461-499. Milano: Pont. Univ. Santa Croce, 2000.

Gullo, Carlo. "Il ricorso gerarchico: procedura e decisione". En La giustizia ammnistrativa nella Chiesa, 85-96. Città del Vaticano: Librería Editrice Vaticana, 1991.

Labandeira, Eduardo. En Manual de Derecho Canónico, Juan Ignacio Arrieta, et al., obra a cargo del Instituto Martín de Azpilcueta, 719764. Pamplona: Eunsa, 1988.

-. "El recurso jerárquico ante la Curia Romana". Ius Canonicum 30 (1990): 449-465.

—. "La defensa de los administrados en el Derecho Canónico". Ius Canonicum 61 (1991): 271-288.

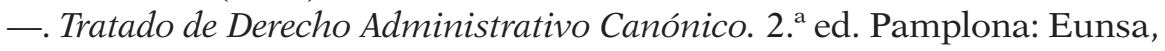
1993.

Luca, Luigi de. "L'avvocato tra il privato e l'autorità nell'ordinamento canonico". En Scritti vari di diritto ecclesiastico e canonico. Vol. 1. Padova: Cedam, 1997.

Martens, Kurt. "Protection of Rights: Experiences with Hiercachical Recourse and Possibilities for the Future". Jur 69 (2009): 646-707.

Miras, Jorge, Javier Canosa y Eduardo Baura. Compendio de derecho administrativo canónico. Pamplona: Eunsa, 2001.

-. "Recurso jerárquico". En Diccionario General de Derecho Canónico, editado y coordinado por Javier Otaduy, Antonio Viana y Joaquín Sedano, 775-778. Vol. 4. Pamplona: Thomson Reuters Aranzadi, 2012.

Montini, Gian Paolo. "Modalità procedurali e processuali per la difesa dei diritti dei fedeli. Il ricorso gerarchico. Il ricorso alla Segnatura Apostolica”. Quaderni di diritto ecclesiale 8 (1995): 287-320.

—. "La giustizia ammnistrativa dal Concilio al Codice". Periodica 102 (2013): 641-677. 
Mur Malagón, Luis Bernardo. "Del recurso contra los decretos administrativos" (Cann. 1732-1739)". Universitas Canonica 44 (2011): 233-256.

Ochoa, Xavier. "La figura canónica del procurador y abogado público". En Dilexit Iustitiam. Studi in honorem Aurelii, Card. Sabattani, dirigido por Zenon Grocholewski y Vicente Cárcel Ortí, 249-284. Città del Vaticano: Librería Editrice Vaticana, 1984.

Olivares D'Angelo, Estanislao. "Recurso contra los actos administrativos (Recursus administrativus)". En Diccionario de Derecho Canónico, dirigido por Carlos Corral y José María Urteaga Embid, 532-533. Madrid: Tecnos, 1989.

Ortiz, Miguel Ángel. "I ricorsi gerarchici”. Ius ecclesiae 3 (1999): 683-737.

Parada Vázquez, Ramón. Derecho Administrativo I. Parte General. 13. ed. Madrid: Marcial Pons, 2002.

Pinto, Pio Vito. "El recurso jerárquico". Revista Mexicana de Derecho Canónico 16 (2010): 37-62.

Prieto Castro, Leonardo. Tribunales españoles. Organización y funcionamiento. Madrid: Editorial Tecnos, 1974.

Thériault, Michel. "La procédure des Recours Administratifs: Survol et Évaluation". CLSA Proceedings 57 (1995): 387-427.

Valdrini, Patrick. "Les recours canonques offerts aux animateurs pastoraux". AC 35 (1992): 55-60.

Zamora García, Francisco José. "Resolución del recurso jerárquico canónico". Anuario de Derecho Canónico de la Universidad Católica de Valencia 6 (2017): 15-48.

Zayas, Malaquías. "Abogados y Procuradores en los Tribunales Eclesiásticos". Revista Jurídica de Cataluña 83 (1984): 202-210. 